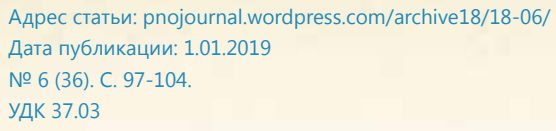

В настоящей статье описан опыт работы авторов с использованием прецедентного текста в практике преподавания немецкого языка будущим учителям иностранных языков. Актуальность статьи обусловливается необходимостью формирования лингвокультурологических компетенций студентов, изучающих иностранный язык, что соответствует современной лингводидактике и требованиям действующего ФГОС. Включение в процесс обучения прецедентных художественных текстов является одним из наиболее эффективных путей формирования лингвокультурологических компетенций и способствует развитию навыков устной и письменной речи на иностранном языке. В результате проведенного исследования доказано, что эффективность работы с прецедентным текстом зависит от организации учебного занятия на всех этапах работы. Важны выбор текста, разработка системы заданий и упражнений, формирующих способность к коммуникации в устной и письменной формах для решения задач межличностного и межкультурного взаимодействия на иностранных языках. Разработанные и представленные в данной статье типы упражнений являются универсальными и могут быть использованы при работе с любым другим прецедентным текстом.

Ключевые слова: обучение иностранным языкам в высшей школе, лингводидактика, лингвокультурологические компетенции, прецедентный текст

\title{
The Use of Precedent Texts to Form the Linguocultural Competence in Foreign Language Teacher Training at Higher School
}

The present article describes the authors' work experience with the use of precedent text in German language in teaching practice for future foreign languages teachers. The article actuality is stipulated by the need to form the linguocultural competence in students studying foreign language, which conforms to modern linguodidactics and to the requirements of the valid Federal Educational Standard (FES). Incorporating the precedent literary texts into the educational process is one of the most efficient ways to form the linguoculturological competence and promotes the development of oral and written language skills in foreign language. The conducted research resulted in evidence that the efficiency of work with the precedent text depends on organizing the teaching lesson on all phases of work. It is important to select the text, develop the system of tasks and exercises forming the communication skills in oral and written forms to solve the objectives of interpersonal and intercultural interaction on foreign languages. The developed and presented in the given article types of exercises are multipurpose ones and may be used in work with any other precedent text.

Key words: foreign language learning at higher school, linguodidactics, linguoculturological competence, precedent text 
дентов, изучающих иностранный язык, особенно если речь идет о подготовке будущих учителей иностранного языка. Это позволит им, помимо двух названных условий, увидеть связь между фактом культуры и словесным выражением, его обозначающим, отказаться от стереотипов при оценке чужой культуры, а также глубже понять свою культуру.

В методической литературе предлагается широкий спектр средств, позволяющих сформировать эти навыки при изучении иностранного языка, к ним относится использование художественных произведений, кинофильмов, мүльтфильмов, фольклорных произведений, фразеологизмов, пословиц, поговорок, крылатых выражений и т.п. на языке оригинала. По своему характеру прецедентный текст является прекрасным источником как языкового, так и культурологического материала, что немаловажно с точки зрения преподавания иностранного языка. Умение употреблять в речи иностранные прецедентные тексты говорит о высоком уровне владения языком, поскольку студент приобретает «способность к иноязычному общению на межкультурном уровне, под которым понимается адекватное взаимодействие с представителями других культур» [6, с. 49]. Студент овладевает вербально-семантическим кодом языка и постигает фрагмент картины мира, что позволяет «понять новую для него социальную действительность» [Там же].

Наш собственный многолетний опыт преподавания в высшей школе и подготовки будущих учителей немецкого языка показывает, что включение в процесс обучения прецедентных художественных текстов является одним из наиболее эффективных путей формирования лингвокультурологических компетенций. Одновременно с этим, использование прецедентных текстов способствует развитию навыков устной и письменной речи на немецком языке.

В каждой культуре формируется свой корпус прецедентных текстов, вызывающий определенные ассоциации у носителей языка данной культуры, который, однако, может быть неизвестен членам других культурных групп, что необходимо учитывать во избежание коммуникативных неудач при межкультурном общении.

Ю.Н. Караулов, автор термина «прецедентные тексты», относит к ним тексты, «значимые для той или иной личности в познавательном и эмоциональном отношениях, имеющие сверхличностный характер, т.е. хорошо известные и широкому окружению данной личности, включая её предшественников и современников, и, наконец, такие, обращение к которым возобновляется неоднократно в дискурсе данной языковой личности» [9, с. 216]. По мнению Ю.Н. Караулова, прецедентные тексты - это лингвокультурологическое явление, являющееся неотьемлемой частью структуры языковой личности 
[9]. Прецедентные феномены позволяют авторам художественных текстов выразить личностное понимание особенностей и противоречий современного мира [16].

В лингвистике имеется много научных работ, посвященных определению феномена прецедентного текста и его видов. Это, прежде всего, исследования известных ученых Е.М. Верещагина и В. Г. Костомарова [5], Ю.Н. Караулова [9], Ю.А. Сорокина и И.М. Михалевой [18] и др.

Ряд исследователей, следуя традиции М. Бахтина, рассматривают прецедентный текст как одно из проявлений чужой речи (Н.Д. Арутюнова [2], С.Е. Крючкова [11], А. Chrabaszcz и К. Gor [27] и др.).

Прецедентные тексты часто выступают предметом исследований в области преподавания русского языка (И.В. Лыткина [12]), а также русского языка как иностранного (Л.М. Гриценко, Т.А. Демидова, М.Е. Бахонная [7], Ю.Е. Прохоров и И.А. Стернин [15], A.V. Maiorov, E.N. Metelkin [28]). Эти исследования затрагивают вопросы формирования лингвокультурологической компетенции наряду с изучением языка во избежание коммуникативных ошибок в иноязычной речи.

Однако научных работ, освещающих проблемы лингводидактики преподавания немецкого языка, крайне мало, что и обуславливают актуальность данного исследования.

В нашей статье предлагается описание собственного опыта использования прецедентных текстов на занятиях по практике речи первого иностранного языка (немецкий язык) в высшей школе, что является целью настоящей статьи.

Задачи:

1. Обоснование выбора прецедентного текста.

2. Определение характера трудностей, с которыми встречается студент при чтении и интерпретации прецедентного текста

3. Разработка комплекса заданий и упражнений для работы с прецедентным художественным текстом для формирования лингвокультурологических компетенций и развития навыков устной и письменной речи на немецком языке.

Практическая значимость исследования: в результате исследования разработан комплекс заданий и упражнений, которые могут быть использованы в процессе вузовского обучения при работе как с данным, так и с другими прецедентными художественными текстами.

Материалы и методы исследования

Исследование проводилось на практических занятиях со студентами 4 курса, обучающимися по направлению 44.03.05 «Педагогическое образование (профиль: иностранный язык и иностранный язык») в рамках дисциплины «Практика речи первого иностранного языка (немецкий язык), аспект «Домашнее чтение».
Домашнее чтение традиционно составляет отдельный аспект практического овладения иностранным языком в искусственных условиях на продвинутом этапе обучения. При работе с художественным произведением на занятиях по домашнему чтению наиболее эффективно происходят процессы формирования обучаемыми собственных мыслей, поиска языковых средств и форм их адекватного выражения в коммуникации.

Студенты получают возможность почувствовать свой прогресс, заключающийся не только в более глубоком понимании все усложняющихся текстов, но и в осмысленном желании читать и активно работать с лексикой, грамматическими явлениями, синтаксическими конструкциями, стилистическими приемами и изобразительновыразительными средствами художественных текстов большего объема.

Исходя из вышесказанного, в качестве материала для домашнего чтения была выбрана повесть У. Пленцдорфа «Новые страдания юного В.» [29], написанная в начале 70-ых годов 20-го века. Данная повесть перекликается с известным значимым для немецкой культуры произведением немецкого классика И.В. Гете «Страдания юного Вертера», т. е. прецедентным текстом. Повесть посвящена проблемам молодых людей, которые, независимо от эпохи и времени, переживают свой период «штурма и дранга».

При решении поставленных задач использовались следующие методы исследования: теоретический анализ работ по исследуемой проблематике, наблюдение, беседа, анализ занятий, обобщение опыта.

Результаты исследования

При планировании системы работы мы исходили из того, что студенты изучили творчество И.В. Гете в рамках дисциплины «История литературы стран изучаемого языка» и знакомы с его произведениями.

Основной задачей преподавателя при работе с данной повестью было обратить внимание студентов на осложненную структуру текста и побудить их узнать прецедентный текст, понять его, а также адекватно интерпретировать. Для этого, преподаватель, предвосхищая возможные трудности при чтении повести «Новые страдания юного В.», обращает внимание на сюжет и композицию, название, имена главных героев, детали описания. С этой целью перед чтением произведения все студенты получают вопросы на образовательном портале для самостоятельной проработки:

Предтекстовое задание для всей группы:

U. Plenzdorf „, Die neuen Leiden des jungen W."

Aufgabenstellung:

1. Den Text lesen.

2. Die Hauptpersonen charakterisieren. 
3. Die Sprache des Textes sowie die Wirkung der Sprache auf die Leser analysieren.

4. Plenzdorfs Werk mit Goethes Werk vergleichen.

5. Den Text aus historischer Sicht verstehen.

Несколько студентов получают индивидуальное задание.

Индивидуальное задание:

Планируемый результат: студенты должны получить информацию о произведении.

Два студента должны подготовить презентацию и ознакомить остальных студентов с творчеством У. Пленцдорфа:

Erstellen Sie eine Präsentation über U. Plenzdorf: das Foto des Autors, seine Biografie, andere Angaben zu seinem Leben, Liste seiner Werke. Nutzen Sie folgende Linktipps:

http://www.dhm.de/lemo/html/biografien/ PlenzdorfUlrich /Eine Biografie mit einigen Querverweisen

http://de.wikipedia.org/wiki/Ulrich Plenzdorf Die Wikipedia-Biografie liefert viele Zusatzinformationen.

Для чтения и обсуждения повесть была разделена на 4 смысловых фрагмента (Pensum). Работа над каждым смысловым фрагментом включала задания, направленные на поиск лингвокультурологических аспектов и активизацию навыков устной речи.

Лексические задания

Планируемый результат: Студенты должны проанализировать языковую базу текста.

Лексические задания включали поиск и анализ использования речевых клише, сокращений, молодежного сленга, жаргонизмов, фразеологических единиц, цитат, аллюзий, интертекста, реалий. Обсуждение проводилось в аудитории в ходе устного опроса и дискуссии.

Задания, связанные с анализом композиции и языка повести

Планируемый результат: Студенты должны определить функциональную нагрузку прецедентного текста в романе и систематизировать в виде сообщения.

Эти задания студенты выполняли письменно и размещали на образовательном портале. Ниже приведены задания и краткие наиболее яркие ответы студентов:

1. Aufbau des Romans: wie die die Komposition des Romans?

Das Werk beschreibt die Handlung auf drei Zeitebenen: das Leben der Hauptperson wird in der Rückperspektive dargestellt. Aus dem sozusagen "Jenseits" gibt die Hauptperson ihre Kommentare zu den einzelnen Situationen ab.

DiegegenwärtigeZeit:Ermittlung und Recherchen des Vaters. Das Werk wird in einzelne Kapitel nicht gegliedert, die Struktur ist durchgehend.

2. Erzählperspektive und sprachliche Gestaltung des Werkes: wie wird dargestellt und beschrieben?

Die Handlung des Werkes wird in verschiedenen Zeitebenen beschrieben. Das Werk beginnt mit den Artikeln in der Zeitung über Tod der Hauptperson Edgar. Edgars Vater spricht mit seinen Freunden Willi, Charlie, mit den Arbeitern in der Malerkolonne, um seinen Sohn im Nachhinein kennen zu lernen und $z u$ verstehen. $A b$ und $z u$ schaltet sich der tote Edgar ein, um alles aus seiner Sicht zu kommentieren. Edgar spricht locker, salopp, seine Sprache ist von Jargon und Slang voll. Der Leser wird oft direkt angesprochen: "Ich war vielleicht ein Idiot, Leute!" Edgar drückt seine Gefühlsregungen aus und sagt: "Ich glaub - denk - mich streift ein Bus". Es werden viele englische Wörter und Ausdrücke gebraucht. Zum Beispiel, "high", "jumpte", hält eine "Speech" oder trägt seinen "Bluejeans-Song" vor.

Поскольку основной целью является соотнесение повести У. Пленцдорфа с романом И.В. Гете, важно было провести параллели между произведениями. Такие задания повышенной трудности, относящиеся не к отдельным фрагментам текста, а требующие работы с текстом в целом, выполнялись студентами в группах по 4-5 человек.

Задания повышенной трудности, направленные на проверку сформированности умения получения, поиска и фиксации прецедентных текстов

Планируемый результат: Студенты должны выявить прецедентные аспекты в романе.

Bezug zum Werk von J.W. Goethe "Die Leiden des jungen Werthers"?

Die Hauptpersonen Edgar und Werther haben gleiche Gefühle. Sie sind von den Zwängen und Vorurteilen der Gesellschaft, in der sie leben, eingeengt und können ihre Fähigkeiten nicht entwickeln. Die Hauptperson Werther findet einen fiktiven Gesprächspartner und schreibt an seinen nicht realen Freund Wilhelm. Edgar benutzt die technischen Errungenschaften seiner Zeit und spricht seine Gedanken auf Tonband. Diese Tonbänder schickt er seinem Freund Willi. Die beiden, Edgar und Werther, verlieben sich in eine verheiratete Frau. Edgar zieht sich wie Werther in sich selbst zurück, weil er auch wie Werther mit der Gesellschaft nicht zu Rande kommen kann. Die beiden sterben. Es besteht aber der Unterschied: Edgar stirbt auf Grund eines Unfalles, und Werther wählt seinen Tod selbst. Es ist interessant, dass Edgar oft Zitate aus dem Werk J.W. Goethe "Die Leiden des jungen Werthers" verwendet.

Задания повышенной трудности, направленные на проверку сформированности умения понимания и преобразования информации

Планируемый результат: Студенты должны определить функциональную нагрузку прецедентного текста в раскрытии образов героев и систематизировать в виде таблицы.

В ходе обсуждения текста произведения в группах и обмена информацией и мнений студент-модератор анализирует и сводит в таблицу результаты дискуссии. 
Die offensichtlichen Parallelen, die gezogen worden sind:

\begin{tabular}{|l|l|}
\hline \multicolumn{1}{|c|}{ Werther } & \multicolumn{1}{|c|}{ Edgar Wibeau } \\
\hline $\begin{array}{l}\text { Er verliebt sich und verlässt seine Heimat wegen dieser } \\
\text { Liebe }\end{array}$ & $\begin{array}{l}\text { Er bekommt viele Probleme und verlässt seine Heimat } \\
\text { wegen Problemen }\end{array}$ \\
\hline Ort: es wird der neue Ort geschildert & $\begin{array}{l}\text { Ort: Es wird der Gartenlaube als Lieblingsort trotz aller } \\
\text { Trostlosigkeit geschildert }\end{array}$ \\
\hline Werther schreibt an einen fiktiven Empfänger & $\begin{array}{l}\text { Edgar spricht auf eine Tonbandkassette und schickt } \\
\text { seinem Freund }\end{array}$ \\
\hline Werther hat Misserfolg in der neuen Welt & Edgar hat Misserfolg in der Malerkolonne \\
\hline Er über den Selbstmord wegen Verzweiflung aus & Es passiert der Unfalltod \\
\hline
\end{tabular}

Задания повышенной трудности, направленные на проверку сформированности компетенций

Планируемый результат: Студенты должны по результату прочитанного сформулировать вывод, обосновать собственную интерпретацию прецедентного текста.

Для контроля сформированных компетенций после прочтения всего произведения студентам предложено выполнить проектную работу в группах самостоятельно и представить на занятии проектный продукт:

Проектное задание 1

Willi schreibt an Edgar

Schreiben Sie einen Brief von Willi an Edgar. In diesem Brief antwortet Willi auf die Fragen, nachdem er die Tonbänder abgehört hat. Welche Ratschläge könnte er seinem Freund geben, was könnte er Edgar von seiner Mutter, von Zuhause und Fleming erzählen. Wie könnte er Edgars Situation einschätzen?

\section{Проектное задание 2}

Grabrede

Stellen Sie sich vor, dass alle Hauptpersonen des Werkes sowie auch verschiedene Menschen, mit denen Edgar zu tun hatte, zur Beerdigung erscheinen. Sie ergreifen das Wort. Formulieren Sie diese Reden an Edgars Grab.

Проектное задание 3

Kommentare

Schreiben Sie, ganz im Stil Edgars/Plenzdorfs, einen Kommentar Edgars zu seinem eigenen Begräbnis. Versuchen Sie dabei, die sprachlichen Besonderheiten Edgars zu imitieren oder in heutige Jugendsprache zu übertragen.

В ходе презентаций проектного продукта контролируется владение новой лексикой, правильность ее употребления как грамматически, так и стилистически. Кроме того, по рецепции и реакции преподаватель может оценить способность к спонтанной речи на немецком языке и продуктивности. На заключительном этапе работы с прецедентным текстом предлагается два задания.

Заключительное письменное задание

Планируемый результат: Студенты должны по результату прочитанного дать собственную оценку произведения.

- Schreiben Sie eine Buchkritik für die Zeitung. Wählen Sie die Zielgruppe. Geben Sie eine begründete Empfehlung darüber ab, ob Plenzdorfs Erzählung als Lektüre für die Gleichaltrigen geeignet ist.

Заключительная дискуссия

Планируемый результат: Студенты должны обсудить итоги прочитанного и изложить собственное осмысление повести:

- (Streit-)Gespräch Goethe versus Plenzdorf

Bilden ein (Streit-)Gespräch zwischen dem Johann Wolfgang Goethe und Ulrich Plenzdorf. Die Probleme:

- Urheberrecht (Stichwort "Ideenklau"),

- Probleme Jugendlicher, die in allen Zeiten gleich sind,

- die veränderten gesellschaftlichen Umstände

- die Sprache

- Unterschiedliche bzw. gleiche Wirkung beider Texte auf die Leser.

\section{Обсуждение результатов}

После оценки и анализа выполненных заданий можно констатировать, что студенты решили поставленные задачи и выявили следующее.

Сюжетная структура, система персонажей и целый ряд деталей повести У. Пленцдорфа ассоциативно связаны с романом И.В. Гёте «Страдания юного Вертера». Обращение к тексту И.В. Гёте позволяет понять мотивы и глубинные качества героя: в повести повторяется ситуация, описанная в свое время в романе И. В. Гёте. Кроме того, при помощи преподавателя было выявлено, что подобные интертекстуальные отсылки - «это прежде всего процесс метафоризации» [1, с .7].

Студенты уже на начальном этапе обратили внимание на название произведений: И.В. Гёте «Страдания юного Вертера» и У. Пленцдорфа "Новые страдания юного В.» и сделали вывод, что ассоциации с текстом Гете задают новое восприятие старого сюжета. Интересно было наблюдение одной студентки, что у Гете герой назван полным именем «Вертер», а в заголовке «Новые страдания юного В.» представлено сокращенное 
имя героя, что, вероятно, важно для переноса действия в современность, для которого характерны ускорение темпа жизни, динамичность и краткость речи.

Студенты отметили схожесть основной темы - любовный треугольник - и композиции двух произведений. Повествование в произведении Й.В. Гете «Страдания юного Вертера» построено в форме писем главного героя Вертера к своему другу. В повести У. Пленцдорфа информация передается через воспоминания родителей, друзей, коллег, комментарии самого Эдгара "с того света", а также цитацию И. В. Гёте. Эдгар пытается реализовать себя как личность, стремится наладить нормальный контакт с окружающими людьми. Вертер также не смог найти себя в условиях равнодушия. Оба героя уходят из жизни, не реализовав своих возможностей в полной мере. Обращение к роману И.В. Гёте обогащает текст повести У. Пленцдорфа. Подобная высокая аллюзивная плотность не только помогает правильно прочесть современную повесть.

Интересно, что в ходе прочтения повести студенты самостоятельно выявили отсылки к другим текстам. Например, Эдгар, как и герой романа Д. Д. Сэлинджера «Над пропастью во ржи» Холден Колфилд, в откровенной форме рассказывает о своем обострённом восприятии современной действительности и неприятии морали современного общества. Ассоциации с романом Д. Дефо «Робинзон Крузо» усиливает такую трактовку - одиночество героя и его стремление изменить жизнь вокруг.

Глубокое прочтение и понимание стали возможны благодаря соблюдению следующих условий: тщательный подход к выбору художественного произведения, разработка заданий и упражнений, нацеленных на формирование лингвокультурологических и языковых компетенций.
Заключение

Современная тенденция в обучении иностранного, в частности, немецкого языка предполагает совершенствование коммуникативных навыков и знаний, позволяющих вывести студентов на принципиально иной уровень общения, приближенный к коммуникации носителей языка в естественных речевых условиях.

Как показало проведенное исследование, использование прецедентных текстов на занятиях по практическому курсу первого иностранного языка (немецкий язык) дидактически оправдано. Художественный прецедентный текст позволяет изучать немецкий язык с опорой на специфику национальной культуры, формирует лингвокультурологические и коммуникативные компетенции, что является важнейшими принципами практики преподавания иностранного языка в высшей школе в современных условиях.

Эффективность работы с прецедентным текстом на иностранном языке напрямую зависит от особой организации учебного занятия на всех этапах работы - от подготовительного до заключительного. Помимо заданий, направленных на узнавание, понимание и интерпретацию художественного текста, необходимо разработать лексические упражнения. Такие задания снимают трудности при чтении оригинального текста, способствуют обогащению лексического запаса обучающихся и формируют способность к коммуникации в устной и письменной формах на иностранном языке для решения задач межличностного и межкультурного взаимодействия. Именно такую задачу ставит сегодня современный Федеральный государственный образовательный стандарт.

Разработанные и представленные в данной статье типы упражнений являются универсальными и могут быть использованы при работе с любым другим прецедентным текстом.

ЛИТЕРАТУРА

1. Акашева Т.В. Интертекстуальность как средство разрушения мифов в творчестве Э. Елинек // Вестник Челябинского государственного университета. Челябинск. 2009. Вып. 30. С. 6-10.

2. Арутюнова Н.Д. Диалогическая цитация (к проблеме чужой речи) // Вопросы языкознания. 1986. №1. С.50-54.

3. Бахтин М. М. Эстетика словесного творчества. М.: Искусство, 1986. С. 336-373.

4. Введенская Л.А. Культура речи. Ростов-на-Дону: Феникс, 2001. 234 с.

5. Верещагин Е.М., Костомаров В.Г. Лингвострановедческая теория слова. М.: Русский язык. 1980. 320 с.

6. Гальскова Н. Д. Современная методика обучения иностранным языкам. Пособие для учителя. М.: АрктиГлосса. 2000. 165 с.

7. Гриценко Л. М., Демидова Т.А., Бахонная М.Е. Прецедентные тексты на уроках русского языка как иностранного // Научный журнал КубГАУ. 2017. №126 (02). С. 1-13.

8. Дюжева М.Б.Прецедентность как ключевое понятие лингвокультурологии [Электронный peсурc] URL: http://cyberleninka.ru/article/n/pretsedentnost-kak-klyuchevoe-ponyatie-lingvokulturologii (Дата обращения: 1.06.2018).

9. Караулов Ю. Н. Русский язык и языковая личность. М.: КомКнига. 2006. 261 с.

10. Костомаров В. Г. Как тексты становятся прецедентными // Русский язык за рубежом. 1994. № 1. С.73-76.

11. Крючкова С. Е. Диалоговедение М. Бахтина и теория аргументации // Культурное наследие России. 2016. Т. 15. № 4. С. 20-25.

12. Лыткина И. В. Обучение студентов употреблению прецедентных текстов: дис. ... канд. пед. наук: 13.00 .02$. 
М., 2003. 157 c.

13. Маслова В. А. Лингвокультурология. М.: Издательский центр «Академия». 2001. 208 с.

14. Пассов Е. И. Сорок лет спустя или сто одна методическая идея. М.: Глосса-Пресс. 2006. 240 с.

15. Прохоров Ю. Е., Стернин И. А. Русское коммуникативное поведение. М.: Флинта: Наука. 2002. 328 с.

16. Рахимова Н.М. Отражение авторского видения мира в художественном рассказе // В мире научных открытий: науч. журн. Красноярск. 2010. № 2 (08), часть 4. С. 19-21.

17. Сафонова В. В. Изучение языков межкультурного общения в контексте диалога культур и цивилизаций. Воронеж: Истоки. 1996. 238 с.

18. Сорокин Ю.А., Михалева, И.М. Прецедентность и смысловая структура художественного текста // Структурносемантический и стилистический анализ художественного текста: сб. науч. тр. Харьков. 1989. С. 113-115.

19. Сысоев П.В. Языковое поликультурное образование // Иностранные языки в школе. 2006. № 4. С. 2-14.

20. Тер-Минасова С. Г. Язык и межкультурная коммуникация. М.: Слово. Slovo. 2000. 624 с.

21. Фаенова М.О. Обучение культуре общения на английском языке. М.: Высшая школа. 1991. 132 с.

22. Формановская Н.И. Культура общения и речевой этикет. 2-е изд. М.: ИКАР. 2005. 250 с.

23. Халеева И. И. Основы теории понимания иноязычной речи (подготовка переводчиков). М.: Высшая школа. 1989. 238 c.

24. Шаклейн В.М. Лингвокультурология ситуации и исследование текста. М., 199. 301 с.

25. Amin T.G., Jeppsson F., Haglund J. Conceptual Metaphor and Embodied Cognition in Science Learning: Introduction to special Issue. International Journal of Science Education. 2015. Vol. 37. № 5-6. P. 745-758.

26. Chelli Saliha The Competency-based Approach in Higher Education [Электронный ресурc]. URL: http://dspace. univ-biskra.dz:8080/jspui/bitstream/123456789/320/1/30.pdf (Дата обращения: 01.06.2018

27. Chrabaszcz A., Gor K. Context effects in the processing of phonolexical ambiguity in L2 // Language Learning. 2014. Vol. 64. No. 3. P. 415-455.

28. Maiorov A.V., Metelkin E.N. Die "deutsche Spur" in der altrussischen Erzählung über die Einnahme Konstantinopels durch die Kreuzritter. Byzantinische Zeitschrift. 2017. Vol. 109. № 2. P. 809-820.

29. Plenzdorf U. Die neuen Leiden des jungen W., Suhrkamp Verlag AG, 2010. $160 \mathrm{~S}$.

30. Zhang Y., Lauer G. How Culture Shapes the Reading of Fairy Tales: a cross-cultural Approach. Comparative Literature Studies. 2015. Vol. 52. № 4. P. 663-681.

REFERENCES

1. Akasheva T.V. Intertextuality as a means of destroying myths in the works of E. Jelinek. Bulletin of Chelyabinsk State University. Chelyabinsk. 2009. Vol. 30. pp. 6-10. (in Russian)

2. Arutyunova N.D. Dialogic citation (to the problem of someone else's speech). Questions of linguistics. 1986. no. 1. pp. 50-54. (in Russian)

3. Bakhtin M. M. Aesthetics of verbal creativity. Moscow, Art Publ., 1986. p. 336-373. (in Russian)

4. Vvedenskaya L.A. A culture of speech. Rostov-on-Don, Phoenix Publ., 2001. 234 p. (in Russian)

5. Vereshchagin E.M., Kostomarov V.G. Linguistic theory of words. Moscow, Russian language Publ.. 1980.320 p. (in Russian)

6. Galskova N.D. Modern methods of teaching foreign languages. The manual for the teacher. Moscow, Arkty Glossa Publ., 2000. 165 p. (in Russian)

7. Gritsenko L.M., Demidova T.A., Bahonnaya M.E. Case texts in Russian as a foreign language class. Scientific journal of KubSAU. 2017. no. 126 (02). pp. 1-13. (in Russian)

8. Dyuzheva M.B. Precedence as a key notion of cultural linguistics [Electronic resource]. Available at: http:// cyberleninka.ru/article/n/pretsedentnost-kak-klyuchevoe-ponyatie-lingvokulturologii (accessed 1.06.2018). (in Russian)

9. Karaulov Yu. N. The Russian language and language personality. Moscow, KomKniga Publ., 2006. 261 p. (in Russian)

10. Kostomarov V. G. How texts become precedent. Russian language abroad. 1994. no. 1. pp. 73-76. (in Russian)

11. Kryuchkova S. E. Bakhtin's Dialogue and Argumentation Theory. Cultural Heritage of Russia. 2016. Vol. 15. no. 4. pp. 20-25. (in Russian)

12. Lytkina I. V. Teaching students to use precedent texts. Diss. PhD Ped. Sci., Moscow, 2003. 157 p. (in Russian)

13. Maslova V. A. Linguoculturology. Moscow, Publishing Center "Academy". 2001. 208 p. (in Russian)

14. Passov E. I. Forty years later, or one hundred and one methodical idea. Moscow, Glossa Press Publ., 2006.240 p. (in Russian)

15. Prokhorov Yu. E., Sternin I. A. Russian Communicative Behavior. Moscow, Flinta: Science Publ., 2002. 328 p. (in Russian)

16. Rakhimova N.M. Reflection of the author's vision of the world in an artistic story. In the world of scientific discoveries. Krasnoyarsk. 2010. no. 2 (08), part 4. pp. 19-21. (in Russian)

17. Safonova V.V. Studying the languages of intercultural communication in the context of a dialogue of cultures and civilizations. Voronezh, Origins Publ., 1996. 238 p. (in Russian)

18. Sorokin Yu.A., Mikhaleva I.M. Precedence and semantic structure of an artistic text // Structural-semantic and 
stylistic analysis of an artistic text: collection of articles. scientific tr. Kharkov. 1989. pp. 113-115. (in Russian)

19. Sysoev P.V. Language multicultural education. Foreign languages at school. 2006. no. 4. pp. 2-14. (in Russian)

20. Ter-Minasova S. G. Language and intercultural communication. Moscow, Slovo Publ., 2000. 624 p. (in Russian)

21. Faenova M.O. Teaching communication culture in English. Moscow, High School Publ., 1991. 132 p. (in Russian)

22. Formanovskaya N.I. Communication culture and speech etiquette. Moscow, IKAR Publ., 2005. 250 p. (in Russian)

23. Khaleeva I.I. Fundamentals of the Theory of Understanding Foreign Language Speech (Translator Training). Moscow, High School Publ., 1989. 238 p. (in Russian)

24. Shaklein V.M. Linguoculturology of the situation and the study of the text. Moscow, $301 \mathrm{p}$. (in Russian)

25. Amin T.G., Jeppsson F., Haglund J. Conceptual Metaphor and Embodied Cognition in Science Learning: Introduction to special Issue. International Journal of Science Education. 2015. Vol. 37. no. 5-6. pp. 745-758.

26. Chelli Saliha The Competency-based Approach in Higher Education [Electronic resource]. Available at: http:// dspace.univ-biskra.dz:8080/jspui/bitstream/123456789/320/1/30.pdf (accessed 1 June 2018)

27. Chrabaszcz A., Gor K. Context effects in the processing of phonolexical ambiguity in L2. Language Learning. 2014. Vol. 64. no. 3. pp. 415-455.

28. Maiorov A.V., Metelkin E.N. Die "deutsche Spur" in der altrussischen Erzählung über die Einnahme Konstantinopels durch die Kreuzritter. Byzantinische Zeitschrift. 2017. Vol. 109. no. 2. pp. 809-820.

29. Plenzdorf U. Die neuen Leiden des jungen W., Suhrkamp Verlag AG, 2010. $160 \mathrm{~S}$.

30. Zhang Y., Lauer G. How Culture Shapes Reading a Fairy Tales: a cross-cultural Approach. Comparative Literature Studies. 2015. Vol. 52. no. 4. pp. 663-681.

Информация об авторах

Акашева Татьяна Валентиновна

(Россия, Магнитогорск)

Кандидат филологических наук, доцент

Зав. кафедрой романо-германской филологии и перевода, доцент

Магнитогорский государственный технический университет им. Г.И. Носова

E-mail: akasheva.tv@yandex.ru

Рахимова Нурия Мухаметовна

(Россия, Магнитогорск)

Кандидат филологических наук

Доцент кафедры романо-германской филологии и перевода

Магнитогорский государственный технический университет им. Г.И. Носова

E-mail: nuria_rahimova@list.ru

\section{Information about the authors \\ Tatiana V. Akasheva \\ (Russia, Magnitogorsk) \\ $\mathrm{PhD}$ in Philological Sciences, Associate Professor}

Head of the Department of Romance-Germanic Philology and Translation, Associate Professor Nosov Magnitogorsk State Technical University E-mail: akasheva.tv@yandex.ru

Nuria M. Rakhimova

(Russia, Magnitogorsk)

PhD in Philological Sciences,

Associate Professor

of the Department of Romance-Germanic Philology and Translation

Nosov Magnitogorsk State Technical University E-mail: nuria_rahimova@list.ru

\section{Ссылка для цитированиягост}

Акашева Т. В., Рахимова Н. М. Использование прецедентных текстов для формирования лингвокультурологических компетенций при подготовке учителя иностранного языка в высшей школе // Перспективы науки и образования. 2018. № 6 (36). C. 97-104. doi: 10.32744/pse.2018.6.10
For Reference ${ }^{\text {APA }}$

Akasheva, T. V., \& Rakhimova, N. M. (2018). The use of precedent texts to form the linguocultural competence in foreign language teacher training at higher school. Perspektivy nauki i obrazovania-Perspectives of Science and Education, 36 (6), 97-104. doi: 10.32744/ pse.2018.6.10. (In Russ., abstr. in Engl.) 